\title{
Patients perspectives on drug shortages in six European hospital settings - a cross sectional study
}

Darija Kuruc Poje ${ }^{1 *}$ D, Domagoj Kifer ${ }^{2}$, Isabelle Huys ${ }^{3}$, Joao Miranda ${ }^{4,5}$, Helena Jenzer ${ }^{6}$, Nenad Miljković ${ }^{7}$, Torsten Hoppe-Tichy ${ }^{8}$, Marcin Bochniarz ${ }^{9}$, Roberto Frontini ${ }^{10}$, David G Schwartz ${ }^{11}$, Vesna Vujić-Aleksić ${ }^{12}$, Lana Nežić ${ }^{12}$, Eleni Rinaki ${ }^{13}$, Leonidas Tzimis ${ }^{13}$, Kim Green $^{8}$, Jelena Jovanić ${ }^{12}$, Bojana Carić $^{12}$, Danijela Mandić ${ }^{12}$, Katarina Vilić ${ }^{\text {, Tomasz Bochenek }}{ }^{14}$, Vesna Bačić Vrca ${ }^{15}$ and Srećko Marušić ${ }^{16}$

\begin{abstract}
Background: It is known that drug shortages represent a major challenge for all stakeholders involved in the process, but there is little evidence regarding insights into patients' awareness and perspectives. This study aimed to investigate the patients-perceived drug shortages experience and their view on outcomes in different European hospital settings. Furthermore, we wanted to explore information preferences on drug shortages.

Methods: A retrospective, cross sectional, a mixed method study was conducted in six European hospital settings. One hospital $(\mathrm{H})$ from each of this country agreed to participate: Bosnia and Herzegovina (H-BiH), Croatia (H-CR), Germany (H-GE), Greece (H-GR), Serbia (H-SE) and Poland (H-PO). Recruitment and data collection was conducted over 27 months from November 2017 until January 2020. Overall, we surveyed 607 patients which completed paper-based questionnaire. Questions related to: general information (demographic data), basic knowledge on drug shortages, drug shortages experienced during hospitalization and information preferences on drug shortage. Differences between hospital settings were analyzed using Chi-squared test or Fisher's exact test. For more complex contingency tables, Monte Carlo simulations ( $N=2000)$ were applied for Fisher's test. Post-hoc hospital-wise analyses were performed using Fisher's exact tests. False discovery rate was controlled using the Bonferroni method. Analyses were performed using R: a language and environment for statistical computing (v 3.6.3).

Results: $6 \%$ of patients reported experiences with drug shortages while hospitalized which led to a deterioration of their health. The majority of affected patients were hospitalized at hematology and/or oncology wards in $\mathrm{H}-\mathrm{BiH}$, $\mathrm{H}-\mathrm{PO}$ and H-GE. H-BiH had the highest number of affected patients $(18.1 \%, \mathrm{~N}=19 / 105, p<0.001)$ while the fewest patients were in $\mathrm{H}$-SE $(1 \%, N=1 / 100, p=0.001)$. In addition, $82.5 \%$, ( $N=501 / 607)$ of respondents wanted to be informed of alternative treatment options if there was a drug shortage without a generic substitute available. Majority of these patients $(66.4 \%, N=386 / 501)$ prefer to be informed by a healthcare professional.
\end{abstract}

\footnotetext{
*Correspondence: darija_kuruc@yahoo.com

'Pharmacy Department, General hospital "dr. Tomislav Bardek", Koprivnica, Croatia

Full list of author information is available at the end of the article
}

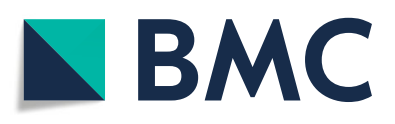

(c) The Author(s). 2021, corrected publication 2021. Open Access This article is licensed under a Creative Commons Attribution 4.0 International License, which permits use, sharing, adaptation, distribution and reproduction in any medium or format, as long as you give appropriate credit to the original author(s) and the source, provide a link to the Creative Commons licence, and indicate if changes were made. The images or other third party material in this article are included in the article's Creative Commons licence, unless indicated otherwise in a credit line to the material. If material is not included in the article's Creative Commons licence and your intended use is not permitted by statutory regulation or exceeds the permitted use, you will need to obtain permission directly from the copyright holder. To view a copy of this licence, visit http://creativecommons.org/ licenses/by/4.0/. The Creative Commons Public Domain Dedication waiver (http://creativecommons.org/publicdomain/zero/1. 0/) applies to the data made available in this article, unless otherwise stated in a credit line to the data. 
Conclusions: Although drug shortages led to serious medical consequences, our findings show that most of the patients did not perceive shortages as a problem. One possible interpretation is that good hospital management practices by healthcare professionals helped to mitigate the perceived impact of shortages. Our study highlights the importance of a good communication especially between patients and healthcare professionals in whom our patients have the greatest trust.

Keywords: Drug shortages, Patient safety, Hospital setting, Patients' perspectives, Europe

\section{Background}

Medicine shortages represent a significant public health problem that deserves the joint attention of governments and industries [1-3]. An increasing number of studies over the past decade report a higher frequency of drug shortages that lead to a high burden of the long-term supplies of key medicines worldwide [1-10]. As the World Health Organization (WHO) has stated, on top of additional costs for health systems, shortages pose risks to the health of patients who fail to receive the medicines they need. This leads to an increased risk of medication errors, adverse drug events or even death [11]. Norepinephrine shortage is one of the best example of that, as is it led to higher in-hospital mortality in patients with septic shock despite the available alternative [12]. In order to reduce these effects, clinicians routinely operate in crisis mode [2]. For instance, the European Association of Hospital Pharmacists (EAHP) found that an increase in drug shortages from 2014 to 2019 had a serious impact on hospital pharmacists' workload [4, 13-15]. EAHP further found that an overwhelming majority of hospital pharmacists $(86 \%-2014$; $92 \%-$ 2018 ; $95 \%$ - 2019) reported that they had current problems with drug shortages in terms of delivering the best care to patients and/or operating the hospital pharmacy. The most affected therapeutic areas were infectious diseases, oncology, emergency medicine, cardiovascular medicine and anesthesia. Similar findings have been reported in Australia, Canada and the USA $[2,3,8,9,12,16]$. Furthermore, the shortage of one medicine has the potential to expand to other generic substitutes or alternatives, and severely limit patient care despite the best mitigation efforts of hospital pharmacists and other healthcare workers $[16,17]$.

Drug shortages represent a major challenge for all stakeholders involved in the process of providing medication (e.g., manufacturers, supply chains, healthcare providers, patients). They lead to significant healthcare burden. The cost and time related to the labor it takes for hospitals to manage drug shortages and maintain quality patient care is 216 million US dollars per year in additional labor costs for pharmacists, pharmacy technicians, physicians, nurses [2]. Consequences of drug shortages also include: increases in drug budget; lost revenue from cancelled infusions and procedures; increased numbers of fulltime pharmacy and technician employees; reallocation of pharmacy resources, which leads to lost productivity and impact in other areas; negative impact on patient care [18]. Among all the problems that stem from drug shortages, patient safety stands out as the most crucial and critical [1, 19-21]. Recent research has demonstrated that patients' perspectives are also important [21]. Michaud et al. investigated experiences of 471 patients with rheumatic diseases in the United States during the COVID-19 pandemic, which led to a hydroxychloroquine shortage [22]. They found that many patients thought that use of immunosuppressive medications increased their risk/potential severity of COVID-19 and that stopping such medications could reduce this risk [22]. The study found that as a result, some patients altered their medications without professional consultation and others because of a hydroxychloroquine shortage. This is a significant finding, as clinicians have to be aware when patients stop taking their medications without a recommendation from a health professional. This highlights the need for studies with insights into patients' awareness and perspectives which can quantify the effect of drug shortages on patient outcomes including in hospital settings. Many studies have been conducted in Canada and the USA while in Europe researchers have rarely studied the patients' perspective from both a clinical impact and patient opinion perspective $[2,4,5,9,12,14,15,22-30]$. Therefore the aim of this study was gathering contemporary data on patients-perceived drug shortages experience and their view on outcomes in different European hospital settings taking into account a humanistic approach. In addition, we wanted to explore information preferences on drug shortages.

\section{Methods \\ Study design}

We conducted retrospective, cross sectional mixed method study in six hospital settings in six European countries. The questionnaire consisted of combined quantitative multiple choice and qualitative open-ended questions. Open-ended questions were included to better explore diverse patients' knowledge on drug shortages and eventually find relationship between their perspectives and outcomes. 


\section{Setting}

From six hospital settings that agreed to participate (located in Bosnia and Herzegovina (H-BiH), Croatia (H$\mathrm{CR})$, Germany (H-GE), Greece (H-GR), Serbia (H-SE) and Poland (H-PO)) two are university hospitals $(\mathrm{H}-\mathrm{BiH}$ and $\mathrm{H}-\mathrm{GE}$ ), two general hospitals (H-CR and H-GR) while two are specialist hospitals (H-SE and $\mathrm{H}-\mathrm{PO})$. Characteristics of hospitals are shown in Table 1.

\section{Participants}

Participants of COST CA15105 ${ }^{1}$ action and EAHP members were invited to take part in this study via meetings, emails and personal contacts. A cover letter explaining the aim of this study together with a patient friendly leaflet and questionnaire was provided. To improve the response rate a principal investigator with the help from EAHP staff, sent reminders for the study via email, an online information platform (EAHP monitor) and social networks. We used non-probability convenience sampling method because it is the least expensive, the least time consuming and one of the most convenient method to use. Additionally, due to limited time that researchers have in their everyday practice and to gather as many different hospitals which are different in size, we decided to have minimal number of respondents per hospital $(N=100)$. Moreover, we expected similar answers from respondents. Recruitment and data collection was conducted over 27 months from November 2017 until January 2020. The extended data collection period was to allow for a wide range of naturally occurring medication shortages, and to enable a large and geographically distributed selection of hospitals to participate. The role of investigators who agreed to participate in the study was to gather approval from the Ethics committee from their hospital, translate questionnaire to their language following guidelines of the $\mathrm{WHO}^{2}$, to recruit patients with explanation of the purpose of the study and to enter the patients' answers into computer base that was created specifically for this study in English language.

Patients completed the survey by paper. In most cases, the survey was administered at hospital discharge while the patient was awaiting his/her discharge letter. Inclusion criteria included at least one day of hospitalization (overnight, inpatient), and being of age 18 years or older.

\section{Questionnaire}

As we did not find questionnaire in the literature that met our expectations, we designed questions based on our professional experiences in dealing with drug shortages. This also included gathering patients' opinions on

\footnotetext{
${ }^{1}$ https://www.cost.eu/actions/CA15105/\#tabs/Name:overview.

${ }^{2}$ Process of translation and adaptation of instruments. link: https:// www.who.int/substance_abuse/research_tools/translation/en/
}

what they consider important when drug shortages occur. At first stage two authors of the study developed a questionnaire which was checked by two experts in drug shortages. Questionnaire was then modified and adapted to their suggestions which they checked again and approved. Subsequently, two other experts and nonexperts in this field corroborated the questionnaire. After final approval, author of the study validated questionnaire on convenience sample of 50 patients (even distribution of both sexes). The validation of the study was done by answering (yes or no) to following questions: if the questions were clear and easy, if the questions covered all problem areas within understanding of proposed "patient friendly" definition on drug shortages, if questionnaire does not lack important questions regarding patients perspectives on drug shortages and if questions do not violate patients privacy. Final questionnaire consisted of sixteen main questions and eight sub-questions (altogether twenty four questions). Fourteen of these were single-selection multiple-choice questions, one was a multi-selection multiple choice question, three were dichotomous questions and six were open-ended. Questions related to general information (demographic data), basic knowledge on drug shortages, drug shortages experienced during hospitalization and information preferences on drug shortage. Furthermore, as authors and pilot tested patients agreed on unambiguous and easy to comprehend drug shortage definition and questions, authors concluded that the questionnaire is reliable. The full questionnaire is available in the supplementary material.

\section{Definition}

For the purpose of this study, we used the following "patient friendly" definition: "A drug shortage is insufficient supply (e.g., from a hospital pharmacy) of a drug that you (a patient) are currently taking without a generic substitute. A generic substitute is a medicine with the same active substance as the drug you (a patient) are taking but produced by another manufacturer."

\section{Ethics committee and informed consent}

The General hospital "dr. Tomislav Bardek" Koprivnica", Croatia, ethics committee (Institutional Review Board) as well as other hospitals (H-BiH, H-GE, H-GR, H-SE and $\mathrm{H}-\mathrm{PO}$ ) that participated in the study approved all aspects of the study and questionnaire. All methods were carried out in accordance with relevant guidelines and regulations. Survey administration was preceded by informed consent. All participant information obtained during the study was kept confidential.

\section{Statistical analysis}

All data are presented in absolute and relative frequencies. Differences are between hospital settings and not 
Table 1 Characteristics of hospitals

\begin{tabular}{|c|c|c|c|c|c|c|}
\hline \multicolumn{7}{|l|}{ Characteristics } \\
\hline Country of hospital setting & $\begin{array}{l}\text { Bosnia and } \\
\text { Herzegovina } \\
\text { (H-BiH) }\end{array}$ & $\begin{array}{l}\text { Croatia } \\
(\mathrm{H}-\mathrm{CR})\end{array}$ & $\begin{array}{l}\text { Germany } \\
(\mathrm{H}-\mathrm{GE})\end{array}$ & $\begin{array}{l}\text { Greece } \\
(\mathrm{H}-\mathrm{GR})\end{array}$ & $\begin{array}{l}\text { Serbia } \\
\text { (H-SE) }\end{array}$ & $\begin{array}{l}\text { Poland } \\
(\mathrm{H}-\mathrm{PO})\end{array}$ \\
\hline Functionality & $\begin{array}{l}\text { Tertiary care } \\
\text { university hospital }\end{array}$ & $\begin{array}{l}\text { Secondary care } \\
\text { general } \\
\text { university } \\
\text { hospital }\end{array}$ & $\begin{array}{l}\text { Tertiary care } \\
\text { university hospital }\end{array}$ & $\begin{array}{l}\text { Secondary } \\
\text { care general } \\
\text { university hospital }\end{array}$ & $\begin{array}{l}\text { Tertiary care } \\
\text { specialist } \\
\text { hospital }\end{array}$ & $\begin{array}{l}\text { Tertiary care } \\
\text { specialist hospital }\end{array}$ \\
\hline $\begin{array}{l}\text { Type of care and } \\
\text { specialization }\end{array}$ & Acute general & Acute general & Acute general & Acute general & Chronic orthopedic & Chronic oncology \\
\hline Number of beds & 1198 & 350 & 2000 & 650 & 550 & 480 \\
\hline $\begin{array}{l}\text { Municipality covered } \\
\text { by hospital }\end{array}$ & $\begin{array}{l}\text { Whole Rebublic } \\
\text { Srpska in Bosnia } \\
\text { and Herzegovina }\end{array}$ & $\begin{array}{l}\text { Municipality of } \\
\text { Koprivnica-Križevci }\end{array}$ & City of Heidelberg & $\begin{array}{l}\text { Municipality } \\
\text { of Chania }\end{array}$ & $\begin{array}{l}\text { Whole country of } \\
\text { Republic of Serbia }\end{array}$ & $\begin{array}{l}\text { Municipality of } \\
\text { Brzozow, } \\
\text { Podkarpackie } \\
\text { voivodship }\end{array}$ \\
\hline $\begin{array}{l}\text { Number of inhabitants } \\
\text { in the municipality } \\
\text { covered by hospital }\end{array}$ & 1142495 & 111782 & 160355 & 108642 & 6945000 & 65000 \\
\hline $\begin{array}{l}\text { Ownership / type of } \\
\text { health system }\end{array}$ & Public & Public & Public & Public & Public & Public \\
\hline
\end{tabular}

between countries. The frequencies of obtained answers were compared with each other between different hospitals. These differences were analyzed using chi-squared test, unless required assumptions were not met (i.e. small sample size) in which case Fisher's exact test was used. For more complex contingency tables, Monte Carlo simulations $(N=2000)$ were applied for Fisher's test. Post-hoc hospital-wise analyses were performed using Fisher's exact tests and false discovery rate was controlled using the Bonferroni method. For age, trends were analyzed using the Cochran-Armitage trend test. Analyses were performed using $R$ : a language and environment for statistical computing (v 3.6.3) [31]. We gave patients ' opinion as a textual answer. As this approach is extremely difficult to analyze and objectively present as size or number and compare attitudes between people, Word cloud was used as the best available option. This graphically shows exactly what patients were thinking and talking about when asked about drug shortages.

\section{Results}

\section{Patients' characteristics}

A total of 607 questionnaires were gathered from six hospitals: H-BiH $(N=105), \mathrm{H}-\mathrm{CR}(N=113), \mathrm{H}-\mathrm{GE}(N=69)$, H-GR $(N=116)$, H-SE $(N=100)$ and H-PO $(N=104)$. From answered questionnaires, 204 and 221 patients did not answer to questions referring to their own definition on drug shortages and preference on information on drug shortages (questions 7 and 16 b)). We excluded hospital from France because of small number of recruited patients $(N=18)$. There was a balanced distribution of female (52\%) and male (48\%) patients' answers. Most patients
(44\%, N=264/607) were between 46 and 65 years (Table 2). Occupation data is provided in the supplementary material. More than half of patients $(51 \%, N=310$ / 607) were hospitalized in a surgical ward, almost half $(45 \%, N=274 / 607)$ in a non-surgical ward and $4 \%(N=$ $23 / 607)$ could not identify the ward in which they were hospitalized. Almost one tenth ( $9 \%, N=53 / 607)$ of patients were transferred from another hospital to support continued medical treatment. Detailed tables are available in the supplementary material.

\section{Patient-perceived drug shortages experience and view on outcomes}

Patents reported if they believed they had been affected by a drug shortage while hospitalized. Of the 607 patients that participated in the study, 6.4\% $(N=39 / 607)$ believed they were affected by a drug shortage while in hospital, $8.2 \%(N=50 / 607)$ did not know and $85.4 \%$ $(N=518 / 607)$ believed they were not affected (Fig. 1). In the 39 cases of perceived drug shortage, most $(51 \% ; N=$ 20/39) were hospitalized in hematology and/or oncology wards in $\mathrm{H}-\mathrm{BiH}, \mathrm{H}-\mathrm{PO}$ and $\mathrm{H}-\mathrm{GE}$.

The hospital with highest level of patient-perceived drug shortage was $\mathrm{H}-\mathrm{BiH}$ with $18.1 \%(\mathrm{~N}=19 / 105)$, with most patients hospitalized in a hematology and oncology ward and in a coronary and cardiology ward $(p<0.001)$. The lowest level of patient-perceived drug shortages was in $\mathrm{H}$-SE with $1 \%(N=1 / 100)$ hospitalized in a spinal surgery ward $(p=0.001)$.

The vast majority $(95 \%, N=37 / 39)$ of hospitalized patients that perceived they were affected by a drug shortage were informed about it by a healthcare professional. 
Table 2 Sex and age - comparisons are made between hospitals

\begin{tabular}{|c|c|c|c|c|c|c|c|c|}
\hline Country, where hospital is located & $\begin{array}{l}\text { Female } \\
\mathrm{N}(\%)\end{array}$ & $\begin{array}{l}\text { Male } \\
\text { N (\%) }\end{array}$ & $\begin{array}{l}18-25 \text { years } \\
N(\%)\end{array}$ & $\begin{array}{l}26-45 \text { years } \\
N(\%)\end{array}$ & $\begin{array}{l}46-65 \text { years } \\
N(\%)\end{array}$ & $\begin{array}{l}66-80 \text { years } \\
N(\%)\end{array}$ & $\begin{array}{l}81-95 \text { years } \\
\mathrm{N}(\%)\end{array}$ & $\begin{array}{l}96 \text { and older } \\
\mathrm{N}(\%)\end{array}$ \\
\hline Greek hospital (H-GR) & $77(66)$ & $39(34)$ & $10(9)$ & $41(35)$ & $29(25)$ & $26(22)$ & $10(9)$ & $0(0)$ \\
\hline Croatian hospital (H-CR) & $44(39)$ & $69(61)$ & $0(0)$ & $13(12)$ & $58(51)$ & $34(30)$ & $8(7)$ & $0(0)$ \\
\hline $\begin{array}{l}\text { Bosnian and Herzegovinian } \\
\text { hospital }(\mathrm{H}-\mathrm{BiH})\end{array}$ & $50(48)$ & $55(52)$ & $6(6)$ & $27(26)$ & $41(39)$ & $27(26)$ & $4(4)$ & $0(0)$ \\
\hline Polish hospital (H-PO) & $55(53)$ & $49(47)$ & $3(3)$ & $21(20)$ & $53(51)$ & $26(25)$ & $1(1)$ & $0(0)$ \\
\hline $\begin{array}{l}\text { Serbian hospital } \\
\text { (H-SE) }\end{array}$ & $65(65)$ & $35(35)$ & $10(10)$ & $14(14)$ & $52(52)$ & $23(23)$ & $1(1)$ & $0(0)$ \\
\hline German hospital (H-GE) & $26(38)$ & $43(62)$ & $2(3)$ & $5(7)$ & $31(45)$ & $22(32)$ & $9(13)$ & $0(0)$ \\
\hline Total N (\%) & $317(52)$ & $290(48)$ & $31(5)$ & $121(20)$ & $264(44)$ & $158(26)$ & $33(5)$ & $0(0)$ \\
\hline
\end{tabular}

In most cases of perceived shortage, if there was no available substitution for the drug, treatment was postponed ( $59 \%, N=23 / 39)$. The highest level of postponements occurred in hematology and/or oncology ward in $\mathrm{H}-\mathrm{BiH}(26.1 \%, N=6 / 23)$ and H-PO $(30.4 \%, N=7 / 23)$. Lack of a substitute drug resulted in treatment cancellation in three cases $(7.7 \%, N=3 / 39)$. Patients were hospitalized in the hematology and/or oncology ward in $\mathrm{H}-\mathrm{BiH}$ and $\mathrm{H}-\mathrm{PO}$, while in $\mathrm{H}-\mathrm{GE}$ patient was hospitalized in the orthopedic ward.

Patients who believed they had been affected by a drug shortage were asked if they believed the drug shortage had negatively affected their health. Of the $35.9 \%(N=$ $14 / 39$ ) of patients who answered that drug shortages had a negative effect on his or her health (e.g., health worsened) (Fig. 2), two thirds of patients $(64.3 \%, N=9 / 14)$ were from $\mathrm{H}-\mathrm{BiH}$ with most $(N=5)$ patients hospitalized in hematology and oncology ward.

An open question allowing patients to express their opinion on how a drug shortage had or might affect their health, was answered by all 607 respondents. The text of these answers was translated into English using Google translate, validated by the co-investigators and

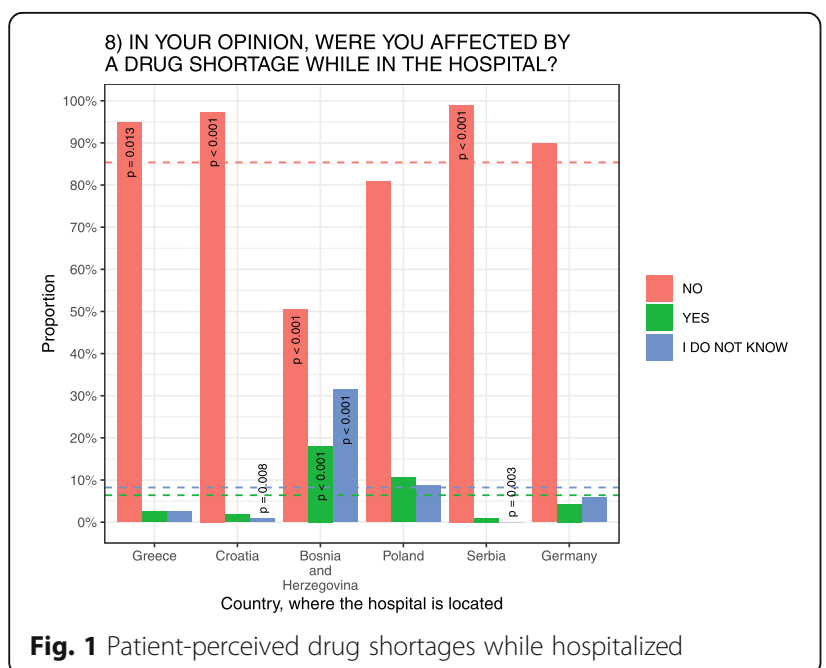

aggregated to produce an illustrative word cloud (Fig. 3) that emphasizes the most common terms used.

\section{Willingness to be informed}

Overall, most patients $(82.5 \%, N=501 / 607)$ from all six hospital settings wanted to be informed of alternative treatment options if there was a drug shortage without a generic substitute available. Majority of patients $(66.4 \%$, $N=386 / 501)$ prefer to be informed by a healthcare professional. Country-specific affirmative response rates from six hospital settings were: Serbia $73 \%(N=73 / 100)$; Croatia $76.1 \%(N=86 / 113)$; Poland $78.8 \%(N=82 / 104)$; Germany $87 \%(N=60 / 69)$, Bosnia and Herzegovina $(90.5 \%, N=95 / 105)$ and Greece $90.5 \%(N=105 / 116)$.

Patients differ in their preferences for receiving information on drug shortages. Figure 4 summarizes patients' preferences on drug shortage information.

\section{Discussion}

Patient-perceived drug shortages experience and view on outcomes

Aim of this study was to investigate the patientsperceived drug shortages experience and their view on

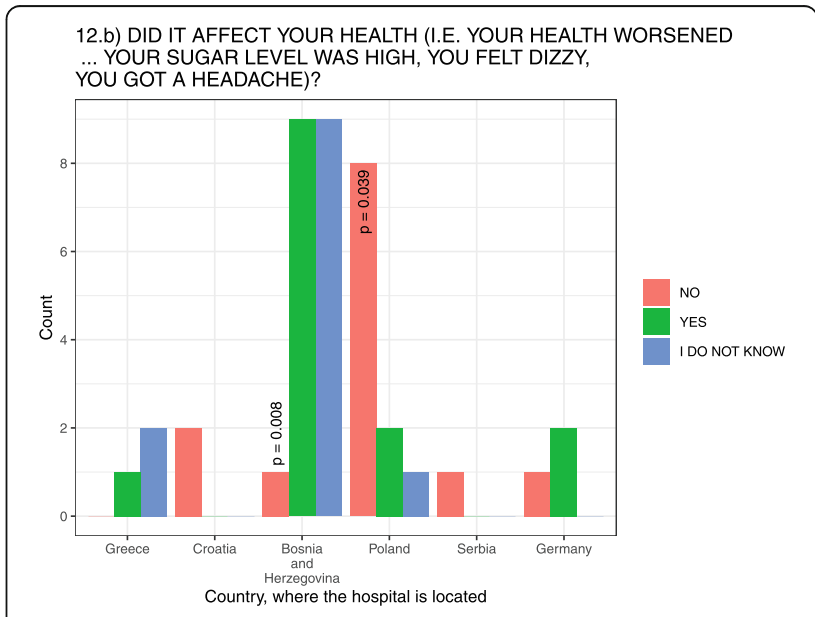

Fig. 2 Patient-perceived drug shortage impact on their health 


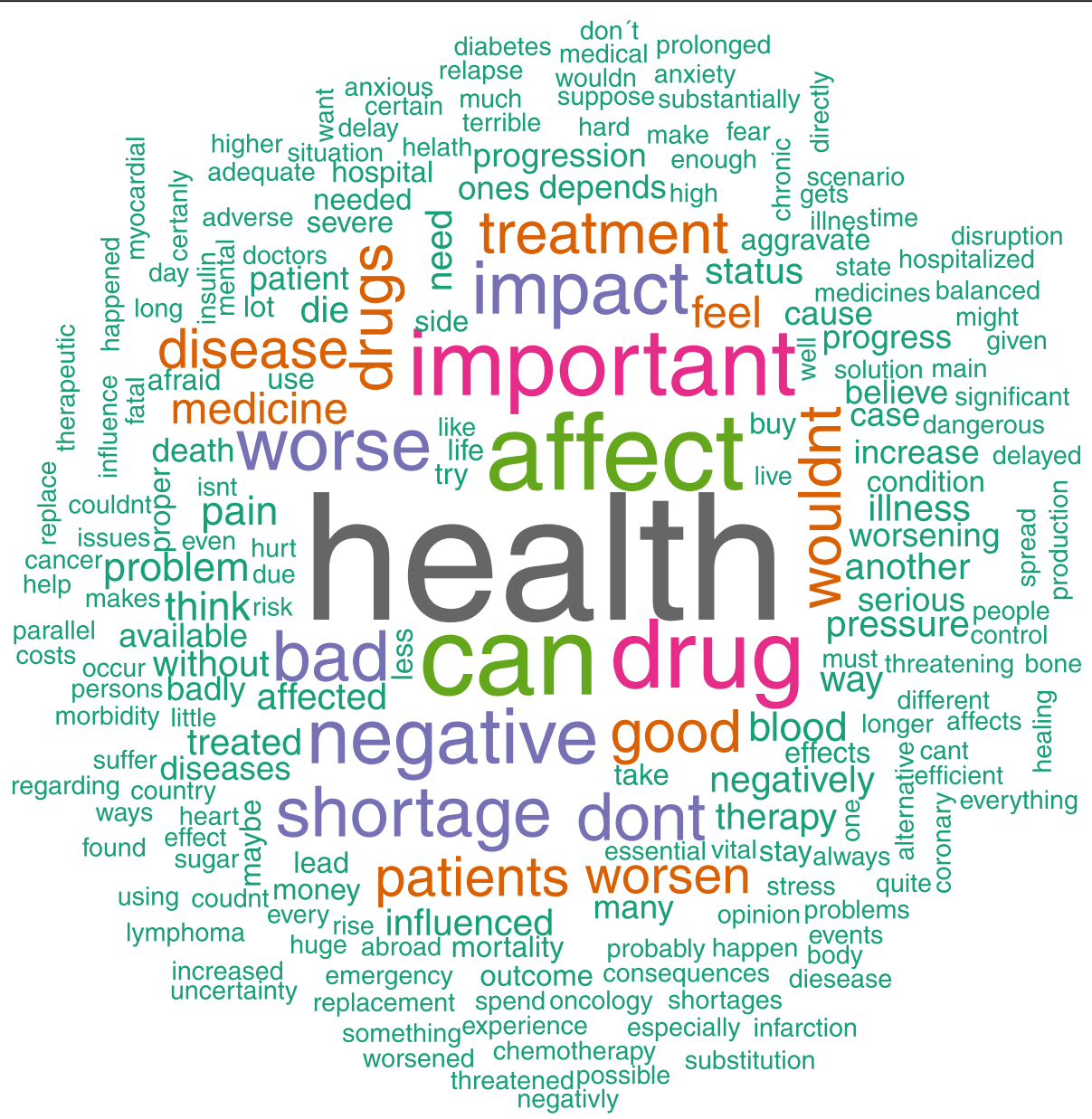

Fig. 3 Opinions of patients on impact of drug shortages on their health

outcomes in different European hospital settings. Our results indicated that, despite an increasing number of studies reporting higher frequency of drug shortages over the past several years $[1-10,13-15]$, only $6 \%$ of patients thought they were affected by drug shortages while hospitalized. This provides new insight into the relationship between hospital pharmacists and other healthcare professionals, who appear to be taking measures to successfully mitigate shortage impact on patient care. The indicated finding is important as healthcare and hospital policies are often inadequate (e.g. current shortage lists are often not providing the real-time shortage information or due to the legal complexities of drug borrowing/distribution, borrowing is restricted to urgent situations and never resolves the shortage) [32]. Consequently, institutions often response in isolation, uncoordinated with each other and management may differ between them. Moreover, hospitals often use different approaches to certain shortages and can be unaware of shortages their neighbors are facing [2].
One of the few studies that reported patient perceptions in Europe was the EAHP 2019 survey [15]. It showed higher frequency of drug shortages, but the question also involved patients' family members who were not hospitalized at the time of the study. Moreover, it included generic substitutes or original medicine that the patient or his/her family member was taking but in lower dose (e.g., "There were patients that were advised to take more pills from a lower dose.") [15]. Our study specifically addressed just patients at the day of discharge from hospital and shortages of drugs that did not have generic substitutes.

We note that according to the 2018 EAHP survey [14] Bosnia and Herzegovina has been identified as the country most affected by drug shortages, in terms of both mean duration and frequency. This provides support to our findings of high levels of patient-reported shortages occurring in that country.

Despite efforts by healthcare professionals to mitigate drug shortages, they often cannot be mitigated. Such 
16) WOULD YOU PREFER INFORMATION ON DRUG SHORTAGES (tick all that apply):

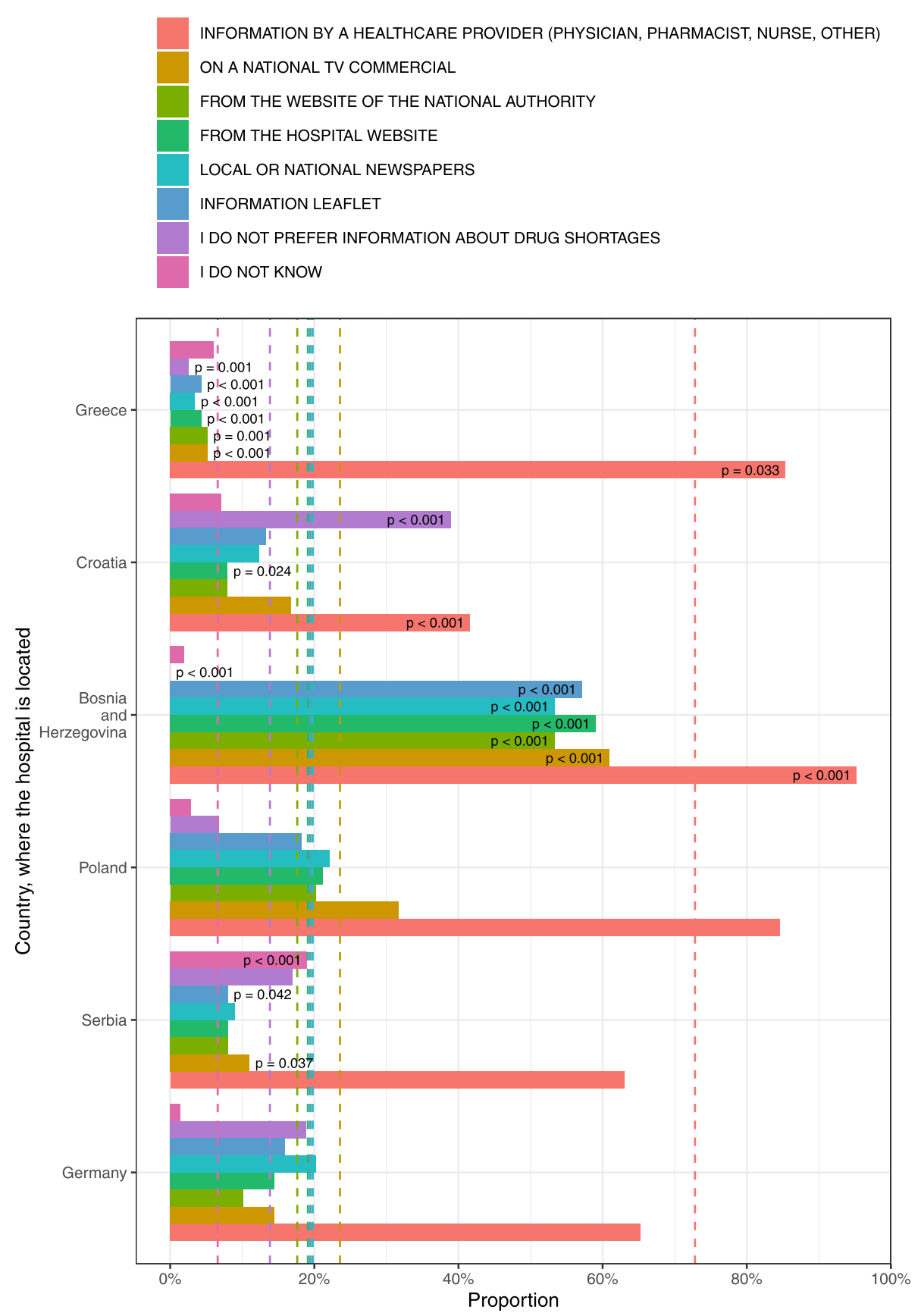

Fig. 4 Patients' preferences on drug shortage information channels

was the case in more than half (51\%) of the affected patients hospitalized at hematology and/or oncology wards. Furthermore, our results should be taken into account when considering that antimicrobial, oncology, emergency and critical care drugs are increasingly unavailable due to pricing or withdrawal from the market. In addition, when they are withdrawn from the market for reasons other than safety or efficacy, there are limited mechanisms to ensure they remain available to patients that need them $[3,7,12,17,33,34]$. This is especially true for those hospitalized in hematology and oncology wards where therapy is time dependent and any delay or cancellation can lead to serious long-term consequences $[1,25,33,35,36]$. Healthcare providers appear to be well 
aware of these problems $[3,4,8-10,12-15,25,28-30]$ as reflected in their role of providing shortage information to affected patients (95\%).

The study demonstrates a correlation between postponed treatment and perceived drug shortages in almost two thirds (59\%) of cases when there was no substitution for the patients' drug while hospitalized. This confirms similar findings from other studies that reported shortages from the healthcare providers' perspective [14, $23,25,28]$. In addition, our findings are in line with a recent systematic review of 40 studies by Phuong et al. that explored predominantly negative impacts of medication shortages on the economic, clinical, and/or humanistic outcomes of patients [37]. However, this review included just a single study of the 40 that examined patients' perspectives on medication shortages, and that study had a single-medication focus (antiepileptic clobazam) while our study considered all affected medicines in shortage.

Notwithstanding the fact that most supply disruptions and drug shortages occur in areas where a good alternative therapy is available, with minimum health implications for patients [19], our results demonstrated drug shortages have clinical significance from the patients point of view as they confirmed that their health worsened due to postponed or cancelled treatment. In addition, this correlates with other respondents who did not experience drug shortages but gave the opinion that shortages could have negative affect on their health.

\section{Willingness to be informed}

This study shows the importance of patients being made aware that there are alternative treatment options when no generic substitute is available. Although, withholding information on drug shortages is done primarily to avoid causing additional patient anxiety, particularly if only minor effects are anticipated [38], informing patients of the alternative treatment process may lead to better outcomes. One example is a research by van Langenberg et al. that showed switching to alternative treatment for ulcerative colitis could have significant impact on patient care with more adverse events (abdominal pain, hepatotoxicity, nausea, hypersensitivity reaction). Patients were actively participating in the study by reporting these adverse events, having been made aware that they were receiving an alternative treatment. All of them had prompt resolution of symptoms upon cessation of alternative therapy [39]. By prioritizing these patients for original treatment when available, possibility of therapy discontinuation and therefore health deterioration is reduced to a minimum.

We suggest that the reason patients from $\mathrm{H}-\mathrm{BiH}$ wanted to be informed of drug shortages through all possible information channels is because of the high levels of patient awareness of drug shortages. In contrast to them, patients from $\mathrm{H}-\mathrm{CR}$ had the least desire to be informed due to less number of affected patients by drug shortages. Lower levels of awareness and not understanding the problem, combined with impatience to be discharged from the hospital as soon as possible, may have resulted in a bias leading to lack of response to the final question of the questionnaire. Moreover, despite the fact that patients from H-SE was the hospital with fewest affected patients, they did not know if they wanted to be informed about drug shortages while hospitalized. This could be due to the immediate impact to awareness caused by participating in this survey, but not being able to decide if this is important or not as had not experienced it.

Our study highlights the importance of a good communication especially between patients and healthcare professionals in whom our patients have the greatest trust. To support this, regulatory authorities should establish carefully planned communication strategies using various tools. These could be the ones preferred by patients in our study such as local or national press releases, television, information leaflets, and websites of national authority.

\section{Limitations and recommendations for the future}

Our primary goal was understanding the perspective of hospitalized patients and this study is not representative of a general population or a general patient population. Due to convenience sampling, after achieving required or almost required minimal number of participants, investigators stopped collecting further data. This explains limitation of our sample size and further studies should survey larger patient populations. While each ethics committee approval was received at each hospital where this survey was administered, a number of hospitals declined approval fearing that interviewed patients would become distressed at the prospect of there having been a drug shortage and may lose trust in the hospital system. Future studies should attempt to address this concern and thus broaden participation. While previous research has focused primarily on hospital pharmacists, our results revealing patients' insights can help create a more robust assessment of and response to drug shortages. We focused solely on the perspectives of hospitalized patients and further studies should include/compare with the perspectives of patients in the community.

\section{Conclusions}

It is important to better understand relationships that might exist between patients' opinions and their acts (e.g., stop taking medicine). Patients' actions are often influenced by their perceptions of the medical environment and the care that they receive. 
Healthcare professionals, especially hospital pharmacists, are on the frontline of drug shortages where they must alleviate the impact on patient care. The fact that only $6 \%$ of patients reported feeling affected by drug shortages without generic substitution is a strong indication that healthcare professionals are successfully mitigating shortages. A further optimistic finding is that $95 \%$ of patients experiencing shortages felt that shortage information was properly delivered by healthcare professionals. Unfortunately, most of the patients affected by drug shortages, hospitalized at hematology and/or oncology wards in $\mathrm{H}-\mathrm{BiH}, \mathrm{H}-\mathrm{PO}$ and $\mathrm{H}-\mathrm{GE}$, and did not have an alternative solution. They reported that their health worsened. $\mathrm{H}-\mathrm{BiH}$ was the most affected. This finding highlights the complexity of the problem, the lack of systemic awareness of drug shortages, and lack of adequate attention from national regulatory bodies in European countries. Establishing systematic, timely and transparent reporting is the foundation of a patient-centered approach to drug shortages. Information provided through various communication channels should provide patients with practical and understandable ways that shortages are being mitigated. Drug shortages will continue to impact patient care however, the approaches we have uncovered and advocated in this study could help mitigate the issue by actively involving patients as a part of a systemic solution.

\begin{abstract}
Abbreviations
COVID-19: Coronavirus disease 2019; EAHP: European Association of Hospital Pharmacists; H: Hospital; H-BiH: Hospital that participated in the study from Bosnia and Herzegovina (University Clinical Centre of Republic of Srpska, Banja Luka); H-CR: Hospital that participated in the study from Croatia (General hospital "dr. Tomislav Bardek", Koprivnica); H-GE: Hospital that participated in the study from Germany (Heidelberg University Hospital, Heidelberg); H-GR: Hospital that participated in the study from Greece (Chania General Hospital "Saint George", Chania, Crete); H-SE: Hospital that participated in the study from Serbia (Institute of Orthopaedic Surgery "Banjica", Belgrade); H-PO: Hospital that participated in the study from Poland (Specialist Hospital Brzozów, Podkarpackie Oncological Center, Brzozów); USA: United States of America; WHO: World Health Organization
\end{abstract}

\section{Supplementary Information}

The online version contains supplementary material available at https://doi. org/10.1186/s12913-021-06721-9.

Additional file 1.

Additional file 2 .

\section{Acknowledgements}

Authors would like to acknowledge COST Action CA15105 - European Medicines Shortages Research Network - addressing supply problems to patients (Medicines Shortages) and EAHP (European Association of Hospital Pharmacists) that aided our efforts. Additionally, we would like to share our gratitude to all hospital teams and all the patients that actively participated and therefore significantly contributed to the study.

\section{Authors' contributions}

DKP conceptualized the study with contribution from HJ. DKP wrote the study. DKP and $I H$ designed the questionnaire with validation from VBV. DKP and KV composed a patient friendly leaflet with validation from JM. DK performed the statistical analysis. NM, THT, MB, WA, LN, ER, LT, KG, JJ, BC, $\mathrm{DM}$ and $\mathrm{KV}$ contributed to data collection carried out in the hospitals. RF and DGS critically revised the manuscript. All authors contributed to manuscript revision, read, and approved the submitted version.

\section{Funding}

Not applicable.

\section{Availability of data and materials}

The datasets generated during and/or analysed during the current study are available from the corresponding author on reasonable request.

\section{Declarations}

\section{Ethics approval and consent to participate}

The General hospital "dr. Tomislav Bardek" Koprivnica", Croatia, the main ethics committee (Institutional Review Board) approved all aspects of the study and questionnaire with reference numbers: 053 - 02/17 - 01/107 and 2137-15-01-17-02. Additionally, co-investigators who agreed to participate in data collection translated survey questions and verified them for accuracy and appropriate understanding of the country-specific arrangements by checking documents, legal acts, and regulations pertinent to each country. All methods were carried out in accordance with relevant guidelines and regulations. Survey administration was preceded by informed consent to participate. All participant information obtained during the study was kept confidential.

\section{Consent for publication}

Not applicable

\section{Competing interests}

The authors declare that the research was conducted in the absence of any commercial or financial relationships that could be construed as a potential conflict of interest.

\section{Author details}

"Pharmacy Department, General hospital "dr. Tomislav Bardek", Koprivnica, Croatia. 'Department of Biophysics, Faculty of Pharmacy and Biochemistry, University of Zagreb, Zagreb, Croatia. ${ }^{3}$ Department of Pharmaceutical and Pharmacological Sciences, KU Leuven, Leuven, Belgium. ${ }^{4}$ Departamento de Tecnologias, Escola Superior de Tecnologia e Gestão, Instituto Politécnico de Portalegre, Portalegre, Portugal. ${ }^{5}$ CERENA - Centro de Recursos Naturais e Ambiente, Instituto Superior Técnico, Universidade de Lisboa, Lisboa, Portugal. ${ }^{6}$ Berner Fachhochschule Health Professions Ernährung und Diätetik, Zürich, Switzerland. ${ }^{7}$ Pharmacy Department, Institute of Orthopaedic Surgery "Banjica", Belgrade, Serbia. ${ }^{8}$ Pharmacy Department, Heidelberg University Hospital, Heidelberg, Germany. ${ }^{9}$ Specialist Hospital Brzozów, Podkarpackie Oncological Center, Brzozów, Poland. ${ }^{10}$ European Association of Hospital Pharmacists (EAHP), Brussels, Belgium. ${ }^{11}$ School of Business, Bar-llan University, Ramat Gan, Israel. ${ }^{12}$ Faculty of Medicine, University of Banja Luka, Banja Luka, Bosnia and Herzegovina. ${ }^{13}$ Hospital pharmacy, Chania General Hospital "Saint George", Crete, Chania, Greece. ${ }^{14}$ Department of Drug Management, Faculty of Health Sciences, Jagiellonian University Medical College, Kraków, Poland. ${ }^{15}$ Pharmacy Department, Clinical hospital Dubrava, Zagreb, Croatia. ${ }^{16}$ Endocrinology Department, Clinical hospital Dubrava, Zagreb, Croatia.

Received: 28 January 2021 Accepted: 30 June 202

Published online: 12 July 2021

\section{References}

1. Woodcock J, Wosinska M. Economic and technological drivers of generic sterile injectable drug shortages. Clin Pharmacol Ther. 2013;93(2):170-6.

2. Fox ER, Sweet BV, Jensen V. Drug shortages: a complex health care crisis. Mayo Clin Proc. 2014;89(3):361-373. 
3. Hawley KL, Mazer-Amirshahi M, Zocchi MS, Fox ER, Pines JM. Longitudinal Trends in U.S. Drug Shortages for Medications Used in Emergency Departments (2001-2014). Acad Emerg Med. 2016;23(1):63-9.

4. Miljković N, Gibbons N, Batista A, Fitzpatrick RW, Underhill J, Horák P. Results of EAHP's 2018 Survey on Medicines Shortages. Eur J Hosp Pharm. 2019;2: 60-65;doi: https://doi.org/10.1136/ejhpharm-2018-001835.

5. Bochenek T, Abilova V, Alkan A, Asanin B, de Miguel Beriain I, Besovic Z, et al. Systematic measures and legislative and organizational frameworks aimed at preventing or mitigating drug shortages in 28 European and Western Asian countries. Front. Pharmacol. 2018;8:942;doi: https://doi.org/1 0.3389/fphar.2017.00942.

6. Benhabib A, loughlissen S, Ratignier-Carbonneil C, Maison P. The French reporting system for drug shortages: description and trends from 2012 to 2018: an observational retrospective study. BMJ Open. 2020;10(3):e034033; doi: https://doi.org/10.1136/bmjopen-2019-034033.

7. Zhu Y, Wang Y, Sun X, Li X. Availability, Price and Affordability of Anticancer Medicines: Evidence from Two Cross-Sectional Surveys in the Jiangsu Province, China. Int J Environ Res Public Health. 2019;16(19):3728;doi:https:// doi.org/10.3390/ijerph16193728.

8. Medicine shortages in Australia: a snapshot of shortages in Australian hospitals. Melbourne: The Society of Hospital Pharmacists Australia. 2017. https://www. shpa.org.au/sites/default/files/uploaded-content/website-content/Submissions/ medicines_shortages_in_australia.pdf. Accessed: 25.05.2020.

9. Canadian Pharmacists Association. Canadian Drug Shortages Survey: Final Report. 2010. Ottawa: Canadian Pharmacists Association. https://www.pha rmacists.ca/cpha-ca/assets/File/cpha-on-the-issues/DrugShortagesReport.pdf. Accessed: 14.06.2020.

10. Canadian Pharmacists Association (CPhA). CPhA Drug Shortages and Recalls Survey 2018. 2019. Ottawa: Canadian Pharmacists Association. https://www. pharmacists.ca/cpha-ca/assets/File/cpha-on-the-issues/CPhADrugShortagesa ndRecallsSurvey2018.pdf. Accessed: 24.06.2020.

11. WHO. Medicines shortages. Global approaches to addressing shortages of essential medicines in health systems. WHO Drug Inf. 2016;30:180-85.

12. Vail $\mathrm{E}$, Gershengorn HB, Hua M, Walkey AJ, Rubenfeld G, Wunsch $H$. Association Between US Norepinephrine Shortage and Mortality Among Patients With Septic Shock. JAMA. 2017;317(14):1433-1442.

13. European Association of Hospital Pharmacists (EAHP). EAHP's 2014 survey of the medicines shortage problem. 2014. https://www.eahp.eu/practice-andpolicy/medicines-shortages/2014-medicines-shortage-survey. Accessed: 28. 06.2020 .

14. European Association of Hospital Pharmacists (EAHP). 2018 Medicines Shortage Survey. EAHP's 2018 Survey on Medicines Shortages to improve patient outcomes.2018. https://www.eahp.eu/practice-and-policy/medicinesshortages/2018-medicines-shortage-survey. Accessed: 05.07.2020.

15. European Association of Hospital Pharmacists (EAHP). 2019 Medicines Shortage Survey 2020. https://www.eahp.eu/practice-and-policy/medicinesshortages/2019-medicines-shortage-survey. Accessed: 08.07.2020.

16. Mazer-Amirshahi M, Goyal M, Umar SA, Fox ER, Zocchi M, Hawley KL, Pines JM. U.S. drug shortages for medications used in adult critical care (20012016). J Crit Care.2017; 41:283-288.

17. Benge CD, Burka AT. Heparin Drug Shortage Conservation Strategies. Fed Pract. 2019;36(10):449-454.

18. Drug shortages and labor costs, Measuring a hidden cost of drug shortages on U.S. hospitals, June 2019. http://www.vizientinc.com/-/media/ Documents/SitecorePublishingDocuments/Public/NZDrugShortagesLa borCost_FullReport.pdf. Accessed: 30.05.2021.

19. Casassus B. Europe urged to take action on drug shortages. Lancet. 2015; 385(9975):1279-1280.

20. De Weerdt E, Simoens S, Casteels M, Huys I. Clinical, Economic and Policy Implications of Drug Shortages in the European Union. Appl Health Econ Health Policy.2017;15(4):441-445.

21. Gupta DK, Huang SM. Drug shortages in the United States: a critical evaluation of root causes and the need for action. Clin Pharmacol Ther. 2013;93(2):133-5.

22. Michaud K, Wipfler K, Shaw Y, et al. Experiences of Patients With Rheumatic Diseases in the United States During Early Days of the COVID-19 Pandemic [published online ahead of print, 2020 Apr 20]. ACR Open Rheumatol. 2020; https://doi.org/10.1002/acr2.11148.

23. Bible JR, Evans DC, Payne B, Mostafavifar L. Impact of drug shortages on patients receiving parenteral nutrition after laparotomy. J Parenter Enteral Nutr, 2014;38(2): 65S-71S.
24. Hsia IK, Dexter F, Logvinov I, Tankosic N, Ramakrishna H, Brull SJ. Survey of the National Drug Shortage Effect on Anesthesia and Patient Safety: A Patient Perspective. Anesth Analg. 2015;121(2):502-6.

25. McBride A, Holle LM, Westendorf C, Sidebottom M, Griffith N, Muller RJ, et al. National survey on the effect of oncology drug shortages on cancer care. Am J Health Syst Phar. 2013; 70:609-617.

26. Lukmanji S, Sauro KM, Josephson CB, Altura KC, Wiebe S, Jetté N. A longitudinal cohort study on the impact of the clobazam shortage on patients with epilepsy. Epilepsia. 2017;59(2):468-478.

27. Rinaldi F, de Denus S, Nguyen A, Nattel S, Bussières JF. Drug Shortages: Patients and Health Care Providers Are All Drawing the Short Straw. Can J Cardiol. 2017;33(2):283-286.

28. McLaughlin M, Kotis D, Thomson K, Harrison M, Fennessy G, Postelnick M, Scheetz MH. Effects on patient care caused by drug shortages: a survey. J Manag Care Pharm. 2013; 19(9):783-8.

29. Bogaert P, Bochenek T, Prokop A, Pilc A. A Qualitative Approach to a Better Understanding of the Problems Underlying Drug Shortages, as Viewed from Belgian, French and the European Union's Perspectives. PLoS One. 2015; 10(5):e0125691.

30. Bauters T, Claus BO, Norga K, Huys I, Simoens S, Laureys G. Chemotherapy drug shortages in paediatric oncology: A 14-year single-centre experience in Belgium. J Oncol Pharm Pract. 2016;22(6):766-770;doi:https://doi.org/1 $0.1177 / 1078155215610915$

31. R Core Team.2020. R: A language and environment for statistical computing R Foundation for Statistical Computing, Vienna, Austria.

32. Chen E, Goold S, Harrison S, et al. Drug shortage management: A qualitative assessment of a collaborative approach. PLoS One. 2021;16(4):e0243870. Published 2021 Apr 23. doi:https://doi.org/10.1371/journal.pone.0243870

33. Alpern JD, Dunlop SJ, Stauffer WM. Broken drug markets in infectious diseases: Opportunities outside the private sector? PLoS Negl Trop Dis. 2019;13(4):e0007190; doi:https://doi.org/10.1371/journal.pntd.0007190.

34. Nonzee NJ, Luu TH. The Drug Shortage Crisis in the United States: Impact on Cancer Pharmaceutical Safety. Cancer Treat Res. 2019;171:75-92;doi: https://doi.org/10.1007/978-3-319-43896-2_6.

35. Goldsack J. C., Reilly C., Bush C., McElligott S., Bristol M. N., Motanya U. N., et al.Impact of shortages of injectable oncology drugs on patient care. Am. J. Heal. Pharm. 2014;71,571-578;doi:https://doi.org/10.2146/ajhp130569.

36. Metzger ML, Billett A, Link MP. The impact of drug shortages on children with cancer-the example of mechlorethamine. N Engl J Med. 2012;367(26): 2461-2463;doi:https://doi.org/10.1056/NEJMp1212468.

37. Phuong, J. M., Penm, J., Chaar, B., Oldfield, L. D., \& Moles, R. The impacts of medication shortages on patient outcomes: A scoping review. PloS one. 2019;14(5):e0215837; https://doi.org/10.1371/journal.pone.0215837.

38. Schleipman, A.R. and Todorova, I. Discourse, Dissonance, and Dualities: How Drug Shortages Are Understood and Communicated Among Health Care Professionals. Narrative Inquiry in Bioethics. 2020;10(1), 63-78;doi:https://doi. org/10.1353/nib.2020.0012

39. van Langenberg DR, Cheng RK, Garg M. Outcomes of a drug shortage requiring switching in patients with ulcerative colitis. World J Gastrointest Pathophysiol. 2020;11(2):32-42;doi:https://doi.org/10.4291/wjgp.v11.i2.32.

\section{Publisher's Note}

Springer Nature remains neutral with regard to jurisdictional claims in published maps and institutional affiliations.

\section{Ready to submit your research? Choose BMC and benefit from:}

- fast, convenient online submission

- thorough peer review by experienced researchers in your field

- rapid publication on acceptance

- support for research data, including large and complex data types

- gold Open Access which fosters wider collaboration and increased citations

- maximum visibility for your research: over $100 \mathrm{M}$ website views per year

At BMC, research is always in progress.

Learn more biomedcentral.com/submissions 